\title{
The Application of Mind Mapping in the Teaching of Specialized Courses in Medical Colleges
}

\author{
Min Zheng, Xiaolong Liu, Yiping Jia \\ Jiangxi Medical College, Shangrao, Jiangxi, 334000
}

Keywords: Mind Mapping, Medical College, Specialized Courses.

\begin{abstract}
Mind mapping in the brain on the information storage processing has congenital physiological and psychological advantages. That is, from the inside and outside the various information in the brain to form nodes, interrelated, and constantly dynamic processing into a different structure, component size and the existence of different times the so-called / thinking center, and thus divergence (radiation) out of thousands Tens of thousands of hooks (new link). The brain is to rely on such a basic method constitutes a very large, complex neural network or information network, and constantly realize the information input and output, internal and external information exchange. The different functional tendencies of the left and right hemispheres, not only the processing of different types of information with a relatively specialized division of labor, more help to help the two hemisphere function of each other, superimposed and greatly enhance the integration function, strengthen the brain as a whole advanced neural activity.
\end{abstract}

\section{Introduction}

In recent years, China's higher medical education carried out a series of reforms, made a lot of successful experience, but there are many problems: from the teaching process, the current teaching is still taught, that is, inculcation, students are Passive learning, students and teachers, students and students of the basic communication between the no. For a long time, professorship teaching is the most used method of teaching in the classroom, because the classroom system taught in the shortest possible time to transmit the most information, with the least number of teachers to face the most students, and teachers My study experience and scholarship experience summed up to impart to students. But the problem with this teaching method is that students lack communication with teachers, often can not effectively grasp the focus of learning, and rarely have their own thinking on the problem, students around the teachers and textbooks.

From the structure and framework of the knowledge system, the current teaching more attention to specific details, focusing on the depth of knowledge development, students of the overall structure of knowledge and framework not very understanding. The direct result of this is that after completing a course, ask the student what the course is saying, the student can only answer some of the details of the system, but not a whole description of the course, not to mention the application of knowledge solve the real problem.

From the perspective of scientific research and practical ability training, the teaching experiment of most colleges and universities is limited to the verification of existing knowledge and theory, and can not effectively achieve the purpose of cultivating students' independent research and research projects and practical ability. With the development of science, the amount of knowledge soared, students can only learn some of the most basic knowledge during school, it is important to learn how to acquire knowledge, for the future continue to improve lay a solid foundation.

\section{The Basic Content of Thinking Map}

Radioactive thinking is the natural way of thinking the human brain. Mind mapping is an external manifestation of radioactive thinking. Every kind of information into the brain, whether it is feeling, memory or ideas, including text, numbers, symbols, lines, colors, images, rhythm, notes 
and smell, physical form, etc., can become a center of thought, by The center diverges tens of thousands of hooks, each linked to a link to the center theme, and each link can become another central theme, and then out of thousands of hooks, forming a huge of the extremely complex information network. ,.. These structures can be regarded as your memory, that is, your personal database. The accumulation of these massive and complex databases from the beginning of the birth of the brain, the amazing memory of the brain so that we accumulated a lot of information, through the mind map of the radioactive thinking method, in addition to accelerating the accumulation of data, the data will be based on each other The relevance of hierarchical management, so that data storage, management and application due to more systematic and increase the efficiency of brain operation. At the same time, the mind map makes use of the functions of the left and right brain, through their different functional tendencies of collaboration, so that the brain function to show the system, complete, a variety of ways of thinking the role of organic polymerization.

It can be argued that the objective and natural existence of the above-mentioned thinking ability and the way of the human brain itself is the material basis of Tony Bazan's thought mapping. In the case of discovery, he reveals the thought function of the brain; in the case of invention, he suggests that in this way of manpower, the human mind will be expressed. In addition to providing a correct and rapid learning method and tools, the use of creative ideas and convergence, project planning, problem analysis and resolution, conference management planning and testing, etc., in order to provide a correct and rapid learning methods and tools based on radioactive thinking. It also has a surprising effect. It is a way to fully demonstrate the potential of personal intelligence will enhance the thinking skills, significantly enhance the memory, organizational strength and creativity. It has quantum leaping up with traditional notes and learning methods.

\section{The Construction of Application Pattern of Thinking Mapping in Medical Course Teaching}

Before the commencement of the teaching activities, the teacher analyzes the teaching objectives of the whole course and the teaching modules to determine the subject of knowledge that must be grasped in the course of study (ie, the knowledge content related to the basic concepts, basic principles, basic methods or basic processes). Because the subject is included in the teaching content needed for the teaching goal, it is possible to obtain the relationship between the general goal and the sub-goal through the teaching goal analysis, which means that all the knowledge points needed to achieve the teaching goal are obtained. Identify the subject of the current knowledge. In this process, the use of mind mapping to help teachers analyze the relationship between the knowledge points, teachers can not only quickly write lecture notes, so that the focus of difficult knowledge at a glance, and can easily grasp the knowledge system framework and structure, Arrangements are also more handy.

A large number of visual elements in the mind map are conducive to the creation of context, which can effectively promote the learner's construction of the meaning of knowledge. Therefore, the introduction of teachers in the new class, the use of intuitive image, enlightening way of thinking map, you can make the abstract problem of concrete, esoteric principles of visualization, boring knowledge interesting, students perceive through the perception of doubt, find the problem, Cognitive conflict.

Under the guidance of teachers, they complete the overall understanding of the new knowledge, driven by strong curiosity, students with questions to find information, familiar with the teaching content, drawing their own mind map. In this session, teachers should give students the appropriate guidance, such as providing background information to explore the problem and solve the problem of clues and the connection between old and new knowledge, to encourage students to explore the basis of self-doubt, dare / unconventional 0 Put forward personal ideas, and explore the creative thinking potential of students. This process can be divided into three stages, the first stage before the class, students through the study of the classroom to learn the knowledge content, the initial drawing of personal thinking map; teacher teaching is completed, the understanding of knowledge to further deepen, After the class, through the memories and reflection, to consolidate and deepen the understanding of the content of knowledge, the second revision and reconstruction. 
Students self-exploration process of learning, will inevitably encounter problems that do not understand, at this time the advantages of group collaborative learning is reflected. The purpose of collaborative learning is to further improve and deepen the construction of the meaning of the subject through the different strategies of group discussion, negotiation and role play, based on the students' independent inquiry and study. The entire collaborative learning process should be guided by the teacher organization, the discussion can be raised by the teacher can also be raised by the students. In view of the problems existing in the students' study, the teachers divided the students into different groups according to the question, and each group of 3-5 people discussed. The members of the group exchanged their thoughts with each other, and the ideas from the group's minds were drawn from a group of minds. After analyzing and reflecting the first collective mind map, the team members revised the place that needed to be changed and reconstructed the mind map to form the final outcome of the group. Operation should pay attention to the time to master, and to ensure that students in the discussion of communication can express their views, help each other, and jointly improve, so as to develop students' ability to express, spirit of cooperation and team awareness. Teaching teachers to maximize the enthusiasm and creativity of students to discuss, but also should pay attention to timely students to inspire, the trend to control the discussion process.

In the actual teaching process, according to the different teaching content of different courses can also guide to explore a collaborative model to make appropriate adjustments, such as classroom teaching content, then more students can make pre-class preview when the self-exploration study, drawing personal thinking guide Figure, which can save classroom teaching time, but also enable students to learn the content of a preliminary understanding of classroom teaching will become easier.

Divergent thinking, also known as radiation thinking, is the basic form of creative thinking. scattered. Divergent thinking is through imagination, let freedom of thought gallop, through the analysis and combination of information, come to two or more possible answers, ideas or programs. Because the thinkers from different directions, different aspects to think, the answer is certainly more than one, excluding the same answer, others are not taken into account by others, this is the original. It is important to provide students with the opportunity to divergent thinking, to create a situation that can stimulate the thinking of the situation, so that students gradually develop from all directions, multi-angle understanding of things, the habit of solving the problem. Use the mind map to learn it can easily do this. Mind mapping is the most appropriate tool for divergent thinking, which is determined by the characteristics of its radioactive thinking. Radioactive thinking is the natural way of thinking of the human brain, through the mind map of the radioactive thinking method, in addition to accelerating the accumulation of information, the data will be based on the correlation between the hierarchical management, data storage, management and application more systematic and increase the efficiency of brain operation.

\section{Conclusion}

Based on the systematic analysis of domestic and foreign research on the map of the brain, this study has further verified the idea that the researcher had previously thought that the use of the mind map in teaching can increase the relationship between students and teachers, students and students. The thinking of students to better understand and master the overall structure and framework of knowledge content, to solve practical problems to enhance the ability of students to acquire knowledge to be strengthened for the future continuous improvement Lay a solid foundation; thinking map can effectively explore the creative thinking potential of students.

\section{Acknowledgements}

The Application of Mind Mapping in "Biochemistry" Teaching in Higher Medical Colleges Jiangxi Medical College school level issues

JYJY-2017-24 


\section{References}

[1] Zhang Tangfu. Thinking mapping in junior high school English reading teaching application [J]. Students (new concept of education), 2013 (08)

[2] Hu Yongzhong. Using Mind Mapping to Improve English Grammar of Higher Vocational Students [J] .Journal of Qiongzhou University, (2010)

[3] Zou Jing.Using Mind Mapping to Change English Learning Mode [J].Journal of Chongqing University of Science and Technology, 2010 (08)

[4] Huang Xueying, Hu Zhiju. Experimental research on the cultivation of mind mapping into English learning strategies [J]. Foreign Language Teaching, 2009 (03)

[5] Liu Xiaoning. China's mind map research summary [J]. Journal of Sichuan College of Education, 2009 (05) 